\title{
Headache after dural puncture
}

\author{
Simon M Whiteley, Paul G Murphy, Ramez W Kirollos, Stephen R Swindells
}

\section{Headache occurring after spinal anaesthesia may be caused by leakage of cerebrospinal fluid. If symptoms do not resolve after appropriate treatment subdural haematoma should be suspected}

\section{Leeds General Infirmary, Leeds LS1 3EX Simon M Whiteley, registrar in anaesthesia Paul G Murphy, senior registrar in anaesthesia Ramez W Kirollos, registrar in neurosurgery}

St James's University Hospital, Leeds LS9 7TF Stephen R Swindells, consultant anaesthetist

Correspondence to: $\mathrm{Dr}$ Murphy.

BMF 1993;306:917-8
Headache after dural puncture is well recognised by anaesthetists as a complication of spinal anaesthesia. It usually occurs within one to two days of dural puncture and may last for several weeks, although cases persisting up to a year have been reported. ${ }^{1}$ It can be associated with significant neurological sequelae such as cranial nerve palsy and subdural haematoma. ${ }^{1}$ We present a case report which suggests that the awareness of non-anaesthetic medical staff of such potential complications is variable, and that appropriate treatment may therefore be delayed.

\section{Case report}

A fit 41 year old man with no history of neurological problems or head trauma presented for elective inguinal hernia repair. A consultant anaesthetist gave spinal anaesthesia using a 25 gauge Yale spinal needle. Dural puncture was achieved with a single pass and subarachnoid block was established with $4 \mathrm{ml} 0.5 \%$ hyperbaric bupivacaine. Anaesthesia and surgery were uneventful.

On return to the ward the patient complained of headache which became increasingly severe the following day. The headache was worse when he sat up and was associated with neck and shoulder stiffness. The significance of these symptoms was not appreciated and he was discharged later that day.

The headache persisted and he consulted his general practitioner twice over the next month. On each occasion he was reassured that his symptoms were not related to the spinal anaesthetic and was prescribed simple analgesics. These did not relieve his symptoms and he presented to a teaching hospital accident and emergency department one month after the original procedure. At this time he had no focal neurological signs and a senior house officer stated that the headache was not of the usual character and duration of postdural puncture headache, although he was admitted to hospital for bed rest and analgesia. The next day he was seen by a neurological registrar, who diagnosed postdural puncture headache, and he was discharged with simple analgesics and lactulose.

The patient returned to the accident and emergency department 11 days later, still complaining of postural headache and neck stiffness. He had no fever, photophobia, or focal neurological signs, and a senior house officer in neurology diagnosed musculoskeletal neck pain. He was discharged with simple analgesics and diazepam as an anxiolytic and muscle relaxant, with appointments to have outpatient physiotherapy and follow up two weeks later.

Five days later he presented to the accident and emergency department for the third time, complaining of a persistent, non-postural headache that was predominantly occipital, with shooting pains in the left eye. On examination he was noted to be vague, sluggish to obey commands, and ataxic. He was admitted to a neurology ward for analgesia and observation. Computed tomography of the head showed an extensive left sided parietal subdural haematoma with midline shift and contralateral dilatation of the horns of the lateral ventricle (figure). He was immediately transferred to the local neuro-

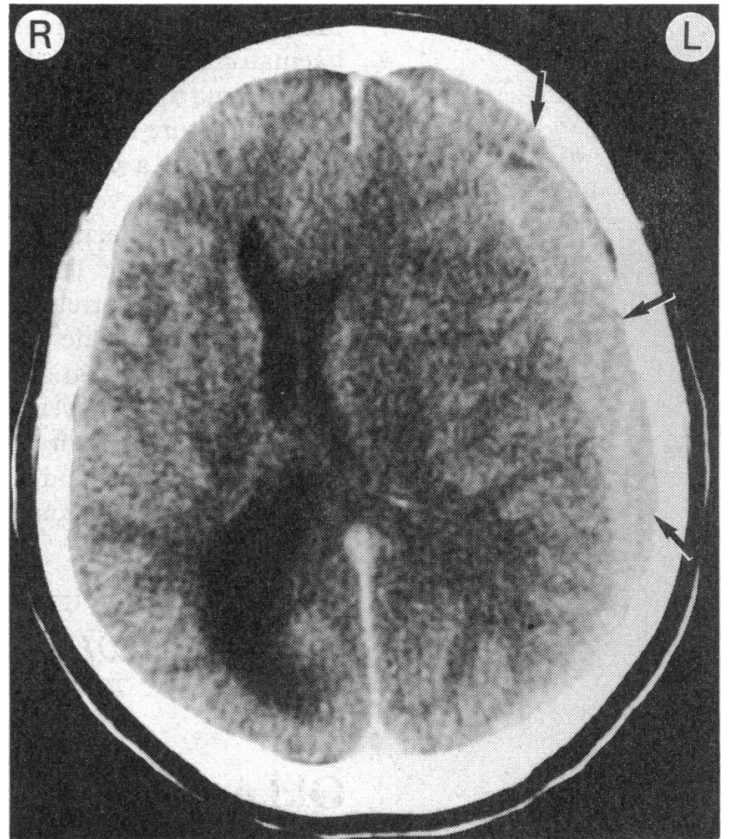

Axial computed tomography of head without intravenous contrast enhancement showing large, slightly hyperdense subdural haematoma over the left cerebral convexity (arrowed), causing severe midline shift to the right and contralateral hydrocephalus

surgical unit for urgent evacuation of the subdural haematoma. At operation a large amount of altered blood was removed. He subsequently made a complete and uneventful recovery.

\section{Discussion}

Postdural puncture headache is a well recognised complication of spinal anaesthesia, the incidence and severity of which depends on several factors including the age of the patient and the size of the dural tear. ${ }^{1}$ It usually presents as a throbbing, occipital headache, which can be incapacitating, and may be associated with neck stiffness, nausea, and photophobia. The headache is characteristically postural, being relieved when the patient is supine or prone and worsened when upright. It is caused by leakage of cerebrospinal fluid through the punctured dura, which results in sagging of the cranial contents and traction on the sensitive meninges. It can arise after any procedure in which the dura is punctured, including spinal anaesthesia, diagnostic lumbar puncture, lumber myelography, and inadvertent dural tap during epidural anaesthesia. Conservative treatment consists of bed rest in the supine or prone position, adequate hydration, analgesia, and the wearing of an abdominal binder (to increase epidural pressure and reduce leakage of cerebrospinal fluid). Persistent or severe headaches justify more invasive treatment. Intermittent injection or continuous infusions of physiological saline epidurally may help prevent or treat the headache, but the most effective treatment is the epidural blood patch. Under aseptic conditions $10-20 \mathrm{ml}$ of autologous blood is injected into the epidural space at the level of the dural puncture. The success rate of the procedure 
is $90-95 \% .^{2}$ Short term complications include back and neck ache, transient fever, and radicular pain; serious long term problems seem to be rare. ${ }^{3}$

Subdural haematoma is a rare but potentially fatal complication of dural puncture. ${ }^{34}$ It is probably caused by traction on the meninges inducing tearing of dural vessels. It is unclear whether bleeding occurs at the time of dural puncture or later as a result of persistent leakage of cerebrospinal fluid. Although there was no evidence of appreciable fresh bleeding at operation or on computed tomography in our patient, the time between dural puncture and evacuation of the haematoma (seven weeks) would have allowed a late haematoma to acquire an elderly appearance. The clear postural nature of the initial headache, and the change in symptoms a few days before the patient's final presentation, suggests that it was a relatively late event and might have been prevented by early epidural blood patching. There is little doubt that earlier aggressive investigation and treatment would have avoided the final, potentially life threatening episode of intracerebral decompensation.

This case raises several points. Ward staff should be alerted to the possibility of a headache after epidural or spinal anaesthesia, and patients should be seen by an anaesthetist before discharge. However, early dis- charge after vaginal delivery or minor surgery means that postdural puncture headaches may not evolve while the patient is in hospital. Patients receiving spinal or epidural anaesthesia should therefore be warned of the possibility of headache and be given clear instructions to refer back to an appropriate medical practitioner in the hospital should any problems occur. In addition, general practitioners and non-anaesthetic hospital medical staff should be aware of the importance of headache after dural puncture. Finally, the differential diagnosis of headache following dural puncture should include subdural haematoma, particularly if it does not improve after blood patching or if the clinical features are atypical.

We thank Mr D Price, consultant neurosurgeon, for permission to report this case.

1 Reid JA, Thorburn J. Headache after spinal anaesthesia. Br f Anaesth 1991;67:674-7.

2 Abouleish E, de la Vega S, Blendinger I, Trio T. Long term follow up of epidural blood patch. Anesth Analg 1975;54:459-63.

3 Edelman JD, Wingard DW. Subdural hematomas after lumbar puncture. Anesthesiology 1980;52:166-7.

4 Newrick P, Read D. Subdural haematoma as a complication of spinal anaesthetic. $B M F$ 1982;285:341-2.

(Accepted 20 January 1993)

\title{
Old people's homes: the relatives' view
}

\author{
Mavis Nicholson, Dorothy White
}

On 1 April new arrangements came into force for arranging and funding residential care for elderly people in Britain. From now on those who seem to need full time care will be assessed first by care managers employed by local authority social services departments. This may lead to admission to an old people's home or a nursing home.

Local authorities have been told to consult both users and carers about such decisions. But what about relatives who have not actually been giving care directly?

The Relatives Association was set up last year as a voluntary organisation for the relatives and friends of older people living in residential homes. Below, its vice president, Mavis Nicholson, a journalist and broadcaster whose mother died of Alzheimer's disease in a residential home last year, gives her personal view of being such a relative. And Dorothy White, the association's founder, explains what the future may hold for elderly residents and their relatives.

\section{A home for mother}

Moving someone you love from your home into a Home can never be anything less than upsetting. It is a big decision even when it is a necessary one. For some people it is traumatic, however much they tell themselves it is for the best.

My sister and I were racked with guilt-brain washed, I think, by past notions of old people's homes. They were little better than workhouses, parish run, where unloved nuisances were abandoned. Only heartless children put their parents into them to exist, neglected, until they died. We should surely have got rid of such hang ups by now. But many 60 year olds like myself still have to fight down these very real imaginings.

I sincerely hope my children will not have to fight them when my time comes. I'll leave them a letter of permission, for one thing, taking the onus off them. And, for another, I hope to put my name down for a good home while I'm still capable of making the choice. Ideally I would like to do some voluntary work in the one I have my eye on, so that I'd feel at home there even before I took up residence.

The search for the right home for my mother was gruelling. My sister did most of the groundwork, working on gut reaction, but she found she had little choice. The home we eventually settled on was in fact the only one we could feel positive about. It did not smell of urine, was nicely furnished like a family hotel, and was run by people who seemed naturally affectionate.

But then we came up against some snags in ourselves. My sister was absolutely exhausted from looking after our mother. I felt bad because I hadn't done much of that and here was I about to do even less.

The worst thing about putting your relative in a home is suddenly seeing the person you love in a communal sitting room with all the others who are just like her. On her own, in my sister's house, my mother hadn't seemed pathetic. The privacy had given her some dignity. Now the multiplication struck me as ludicrous, and she was diminished and exposed by it. It had nothing to do with the home itself. I had to make myself get over this reaction. This was life.

\section{SHOCKS FOR RELATIVES}

Another terrible shock came when I arrived to find my mother wearing something that didn't belong to her. I wasn't alone in this. I remember seeing a staid 